\title{
Study of familial pattern in patients with hyperopia
}

\author{
Abstract \\ Purpose: Purpose of the study was: \\ i. To determine the most prevalent type of hyperopia. \\ ii. To determine the familial pattern in patients with hyperopia, including hereditary and \\ genetic model.
}

Methodology: A cross sectional convenient type study was conducted at Eye Department, Mayo hospital, Lahore Pakistan. It included selection of research type, target population, sample size, study design of survey, Perform and dummy tables, sampling method, research methodology, organizational issues, pilots study and work plan. The study was committed in the months of August, September and October 2013. All the sample size was screened for hyperopia. Performa and questionnaire was formed from data collection.

Results: Out of total 100 hyperopic patients, 53(53\%) were female while 47(47\%) were male. $41(41 \%)$ were with the complaint of decreased vision, $13(13 \%)$ were with blurring, $1(1 \%)$ was with watering, $3 \%$ with itching, $6 \%$ with headache and $35 \%$ were with all these combined symptoms. All these patients were usingspectacles and none were using contact lenses. $82(82 \%)$ of these patients were using spectacles for the last 1 year, $16(16 \%)$ for the last 1-3 years and 2(2\%) were using spectacles for the last 4-6 years. Out of total 100 hyperopic patients $89(89 \%)$ were having no ocular history, $10(10 \%)$ were having previous ocular history, while $1(1 \%)$ were unaware of their ocular history. $70(70 \%)$ out of 100 were having no family history of hyperopia, $2(2 \%)$ have father with hyperopia history, $9(9 \%)$ have history of hyperopia in mother, $11(11 \%)$ in their brothers and $8(8 \%)$ were having history of hyperopia in their sisters.

Conclusion: This study showed that no strong family history is associated with hyperopia. Only $11 \%$ of patients had hyperopia in both parents, all exhibiting with the hyperopia and almost clear fundus shows small positive correlation between maternal hyperopia and hyperopia in their children indicating heritable hyperopia susceptibility.

Keywords: refractive error, hyperopia, familial, glasses, history
Volume 8 Issue 2 - 2018

\author{
Iqra Iqbal,' Javaria Asif Bajwa² \\ 'Department of Optometry, The University of Faisalabad, \\ Pakistan \\ ${ }^{2}$ Department of Optometry, King Edward Medical University, \\ Pakistan
}

Correspondence: Javaria Asif Bajwa, Optometry, King Edward Medical University, 302-D, Press Club Housing Scheme, Canal Road Lahore, Pakistan, Tel +03320840 I94,

Email javariabajwa.io@gmail.com

Received: February 16, 2018 | Published: April 26, 2018

\section{Introduction}

Hyperopia is a refractive error in which parallel rays of light entering the eye reach a focal point behind the plane of the retina, while accommodation is maintained in a state of relaxation. ${ }^{1}$ Hyperopia is a visual condition in which, patient can see clearly objects at distant, but have difficulty in seeing near objects. It is a common refractive error in children and adults. The effects of hyperopia greatly depends upon age, magnitude and the condition of accommodative and convergence system. In older children, hyperopia that is not corrected can also affect the learning ability of effected person. ${ }^{2}$ Due to different definitions by different researches, it is difficult to determine the prevalence of hyperopia. ${ }^{3}$ Usually, most of the infants are hyperopic (about +2.00 D) while premature infants can be less hyperopic or myopic. In full term babies, the prevalence of refractive error has a normal bell shaped distribution. ${ }^{4}$ Estimating 4-9\% of babies of 6-9 months of age have hyperopia more than +3.25 . $^{5,6}$ It is also known that the prevalence of hyperopia is $3.6 \%$ in the 1 -year-old children. During infancy, higher levels of astigmatism are with moderate degree of hyperopia. Despite the reduction of prevalence of refractive error, its distribution still peaks toward mild hyperopia. ${ }^{7}$ The prevalence of hyperopia is apparently increased as, with the development of presbyopia, latent hyperopia is becoming manifest ${ }^{8}$ There is effect of ethnicity, but no effect of gender in the prevalence of hyperopia. A study of
1,880 Chinese schoolchildren showed that the hyperopia greater than $+1.25 \mathrm{D}$ has prevalence of only $1.2 \%$. The risk of developing clinical physiologic hyperopia is usually determined by combining the hereditary factors and biological variation. ${ }^{9}$ It is observed that, magnitude and prevalence are more in childhood, but it decreases gradually due to the process of emmetropization. After childhood, there are minor chances of developing physiological hyperopia.

However, pathological hyperopia can be at any age, and it can be associated with diabetes mellitus, tumors or inflammations. As the degree of hyperopia increases, visual acuity decreases because of optical blurriness. Symptoms depends upon the degree of hyperopia, as in young patient and small degree of hyperopia usually patient is asymptomatic. Patient becomes symptomatic in mild hyperopia due to decrease in reserved amplitude of accommodation and if hyperopia is too great, so it will cause asthenopia, blurriness and fatigue while doing near work. The sign and symptoms of hyperopia include blurred vision, red eyes, facial controlling when reading, frequent blinking, asthenopia, decrease binocularity and decrease coordination between hand and eye. The main symptoms in moderate to high degree hyperopia are amblyopia and strabismus in children. If hyperopia remains uncorrected, it may lead to bad motor development in children. ${ }^{10}$ If hyperopia remains uncorrected in infants, it is associated with delays in motor and cognitive development in visual process. ${ }^{11}$ Familial pattern means a same process happening over and over again 
from one generation to the next generation in a family. Refractive errors are the causes the basic visual impairment all over the world. Current researches in genetics believe that loci have genes for refractive error in different manner. It is believed that now it is possible to understand the basic biology of refractive error, by genetic and environmental knowledge with in vivo measurements of biological conditions.

\section{Methods}

A cross sectional convenient type study was conducted at College of Ophthalmology and Allied Vision Sciences in the main OPD of eye department, Mayo Hospital, Lahore during three months. A total of 100 hyperopic patients of both genders were included in the study by non-probability convenient sampling technique. It included selection of research type, target population, sample size, study design of survey, Proforma and dummy tables, sampling method, research methodology, organizational issues, pilots study and work plan. All the sample size was screened for hyperopia. Performa and questionnaire were formed from data collection and question regarding familial



Figure I Out of 100 patients $53 \%$ were females and $47 \%$ were male.

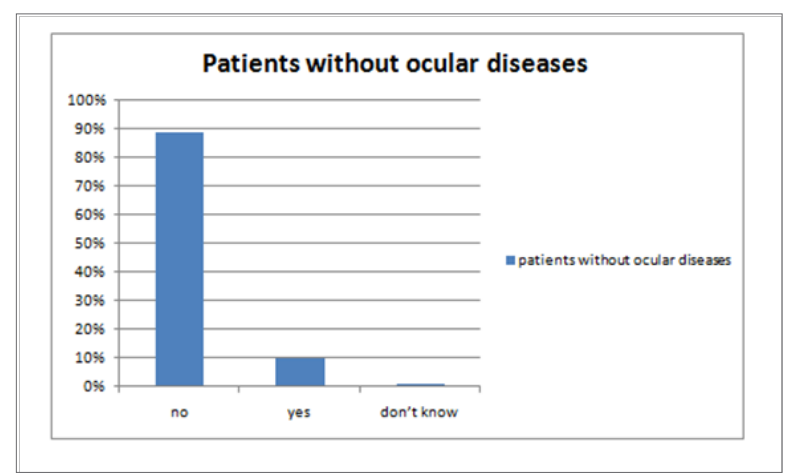

Figure 3 shows the hyperopic patient with any ocular disease history. Out of 100 patients, $89 \%$ were in category of no, $10 \%$ in yes and $1 \%$ in don't know.

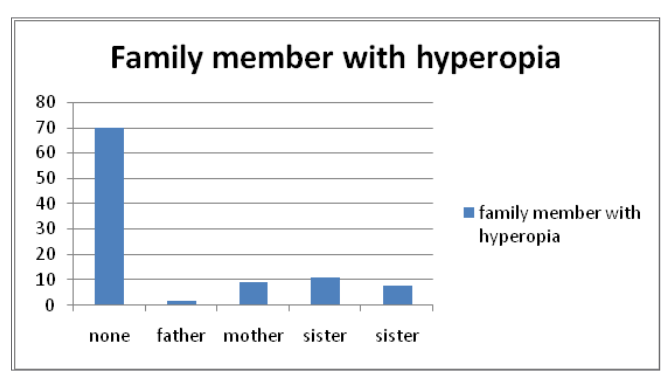

Figure $\mathbf{5}$ Shows the prevalence of family member with hyperopia. Out of 100 patients, $70 \%$ in category none, $2 \%$ in father, $9 \%$ in mother, $11 \%$ in brother and $8 \%$ in sisters. pattern were asked. SPSS 20.00 was used to analyze the data.

\section{Results}

Out of total 100 hyperopic patients, 53(53\%) were female while $47(47 \%)$ were male. $41(41 \%)$ were with the complaint of decreased vision, $13(13 \%)$ were with blurring, $1(1 \%)$ was with watering, $3 \%$ with itching, $6 \%$ with headache and $35 \%$ were with all these combined symptoms. All these patients were using spectacles glasses and none were using contact lenses. $82(82 \%)$ of these patients were using spectacles for the last 1 year, 16(16\%) for the last $1-3$ years and $2(2 \%)$ were using spectacles for the last 4-6 years. Out of total 100 hyperopic patients $89(89 \%)$ were having no ocular history, $10(10 \%)$ were having previous ocular history, while $1(1 \%)$ were unaware of their ocular history. $70(70 \%)$ out of 100 were having no family history of hyperopia, $2(2 \%)$ were having positive family history in their fathers, $9(9 \%)$ were having history in their mothers, $11(11 \%)$ in their brothers and $8(8 \%)$ were having family history of hyperopia in their sisters (Figure 1-5).

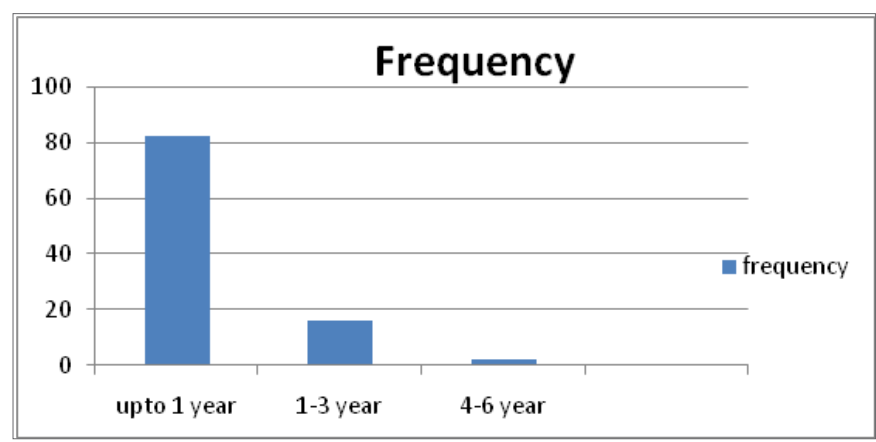

Figure 2 It shows the different categories of duration of using spectacles/ contact lens. Out of 100 patients, $82 \%$ were using up to I year, $16 \%$ were using $\mathrm{I}-3$ years and $2 \%$ using from $4-6$ years.

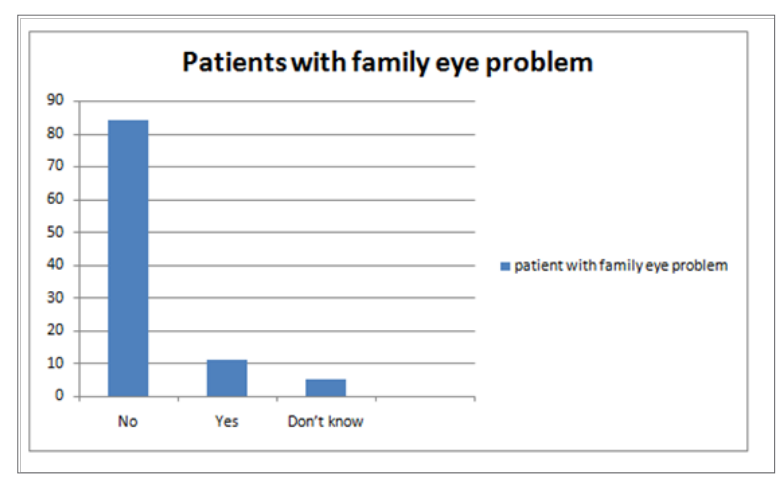

Figure 4 shows hyperopic patient with any family eye problem. Out of 100 patients, $84 \%$ are in category of no. $11 \%$ in yes and $5 \%$ in don't know.

\section{Discussion}

The study shows familial pattern in hyperopic patients. Only $2 \%$ has positive father history of hyperopia, 9 percent has positive mother history of hyperopia, $11 \%$ has positive brother history of hyperopia and $8 \%$ has positive sister history of hyperopia so the siblings has maximum importance positive family history and that is only $19 \%$ so it is not as much high as compared to other refractive errors. According to our study that was done about the correlation between refractive errors and siblings of the patient demonstrate that it is only on the chance base that is great correlation would present. As a twin research was done Thomas's hospital. In this environment and genes were studied by taking different errors of refractions and as a result 
it was found that genetic factor are major factor in the absence or presence of hyperopia and myopia and in case of astigmatism it is seems to be dominantly inherited. ${ }^{12}$ In This study $89 \%$ have no ocular disease history $10 \%$ have positive ocular history and $1 \%$ don't know out of 100 patients.

As a twins study has declared a high rate of inheritance of are refractive error that was up to $90 \%$. Some families demonstrate that one third of population variance is attributable to the effects of shared family environment. While studying 2301 twin pairs it was concluded that there is very low effect of the shared family environment. These differences can be explained by different factors, one is because twins are perfectly age a match and don't include cohort effects so it was concluded family studies has more power to detect shared environmental effect. The analysis shows that $19 \%$ hyperopic patients have refractive error in the paternal family and $11 \%$ have hyperopia in paternal family and on the other hand while seeing maternal history only $28 \%$ patients have maternal history with a refractive error and $13 \%$ have hyperopia in maternal family so according to this study positive maternal family history of hyperopia has more effect on next generation. Refractive errors are disorder of human eye having heterogeneous basis and it is good for genetic order. Different degree of refractive error can cause poor visual development, glaucoma, this disfigurement of surface of cornea, cataract which can ultimately cause detachment in effective person to do treatment that is done to decrease the progression, exact background knowledge of genetic mechanism in different errors is required and also the relationship between environment and genes can be predictable. If we detect refractive error in early stages then it will caused effective and helpful in screening programs. This study explain the genetic model associated with non-syndrome errors of refraction. ${ }^{13}$

\section{Conclusion}

Hyperopia is commonly occurring disease caused by a combination of genes and environment factor but it also concluded that hyperopia has less effect than other type of refractive errors. This study is beneficial in studying the relationship between refractive errors and the effecting factors. As refractive errors are complex heterogeneous disorder of the eye so they can cause bad visual developmental cataract, glaucoma, disfigurement of corneal surface and ultimately detachment. This study showed that no strong family history is associated with hyperopia. Only $11 \%$ of patients had hyperopia in both parents, all exhibiting with the hyperopia and almost clear fundus shows small positive correlation between maternal hyperopia and hyperopia in their children indicating heritable hyperopia susceptibility.

\section{Acknowledgements}

None.

\section{Conflict of interest}

The author declares that there is no conflict of interest.

\section{References}

1. Khurrana AK. Errors of refraction. Theory and practice of optics and refraction. 2008;2:61-62.

2. Williams WR, latif AHA, Hannigtom L, et al. Hyperopia and Educational attainment in primary school cohort. Arch Dis Child. 2005;90(2):150-153.

3. Tarczy K. The epidemiology of early childhood hyperopia. Optom vis sci. 2007;84(2):115-123.

4. Saunders KJ, Woodhouse M, Westall CA. Emmetropisation in human infancy: rate of change is related to initial refractive error. Vision Res. 1995;35(9):1325-1328.

5. Ingram RM, Arnold $\mathrm{P}$, Dally $\mathrm{S}$, et al. The results of a randomized trial of treating abnormal hypermetropia from the age of 6 months. $\mathrm{Br} J$ Ophthalmol. 1990;74(3):158-159.

6. Atkinson J, Braddick O, Nardini M, et al. Infant hyperopia: detection, distribution, changes and correlates-outcomes from the Cambridge infant screening programs. Optom Vis Sci. 2007;84(2):84-96.

7. Kemps GA, Collins SD, Jarman EL. Hyperopic correction. refractive errors in the eyes of children as determined by retinoscopic examination.2008;54:11-123.

8. Morgan M. Changes in refraction over a period of twenty years in a nonvisually selected sample. Am J Optom. 2008;35(6):281-299.

9. Hammond CJ, Snieder H, Gilbert CE, et al. Genes and environment in refractive error: the twin eye study. Invest Ophthalmol Vis Sci. 2001;42(6):1232-1236.

10. Grosvenor T. Refractive state, intelligence test scores, and academic ability. Am J Optom Arch Am Acad Optom. 1970;47(5):355-361.

11. Atkinson J, Braddick O, Nardini M, et al. Infant hyperopia.Detection, distribution, changes and correlates-outcomes from the Cambridge infant screening programs. Optom Vis Sci. 2007;84(2):84-96.

12. Hammond CJ, Snieder H, Gilbert CE, et al. Genes and environment in refractive error: the twin eye study. Invest Ophthalmol Vis Sci. 2001;42(6):1232-1236.

13. Lopes MC, Andrew T, Carbonaro F, et al. Estimating heritability and shared environmental effects for refractive error in twin and family studies. Invest. 2009;50(1):126-131. 